\title{
Kamu ve Özel Sektör Çalışanlarında Bilgi Paylaşma Korkusu
}

\author{
DOI: $10.26466 /$ opus. 868237
}

*

\author{
Bilge Aksay * \\ * Dr. Öğr. Üyesi, Adana Alpaslan Türkeş Bilim ve Teknoloji Üniversitesi \\ İşletme Fakültesi Yönetim Bilişim Sistemleri Bölümü, Adana/ Türkiye \\ E-Posta: baksay@atu.edu.tr \\ ORCID: $0000-0002-0563-7778$
}

\section{Öz}

Günümüz işletmelerinin en değerli varlıkları bilgiye dayanan öz yetkinlikleridir. Örgütlerde bilgi paylaşımının nasıl arttırılabileceğine dair pek çok araştırma bulunmasına karşın, bilgi saklamaya dair çok az çalışma vardır. Çalışanın bilgisini paylaştığı takdirde özgün değerini kaybedeceğgine yönelik algısını ifade eden "bilgi paylaşma korkusu" 2020 Aralık itibariyle google akademik üzerinden aratılmış ve Türkçe hiçbir çalışmaya rastlanılmamıştır. Bu çalışmanın amacı bilgi paylaşma korkusunun Türkçe alanyazına tanıtılması, psikolojik sahiplik teorisi temelinde cinsiyete ve sektör ile pozisyona göre bilgi paylaşma korkusunda farklılık olup olmadığının araştırılmasıdır. Renzl (2008) tarafından geliştirilen bilgi paylaşma korkusu ölçeği kullanılarak, araştırma hipotezleri 225 erkek, 158 kadın beyaz yakalı çalışandan elde edilen verilerle sınanmıştır. Psikolojik sahiplik teorisine göre çalışanlar, üzerinde emek ve zaman harcadıkları şeylere daha çok bağlanarak, sahip oldukları üzerinden kimliklerini tanımlar. Bu araştırmada cinsiyete göre bilgi paylaşma korkusunda farklılık olmadığı varsayımı desteklenmiştir. 2*2 faktöriyel varyans analizi ile kamu ve özel sektörde, yönetici ve çalışan pozisyonunda bulunanlarm bilgi paylaşma korkusu değerlendirilmiştir. Özel sektörde yönetici pozisyonunda bulunanlarda bilgi paylaşma korkusunun istatistiki açıdan anlaml ve diğer gruplardan daha yüksek düzeyde olduğu tespit edilmiştir.

Anahtar Kelimeler: Bilgi paylaşma korkusu, 2*2 faktöriyel desen, beyaz yakalı çalışanlar 
ISSN:2528-9527

E-ISSN : 2528-9535

YIl Year: 11

Cilt Volume: 17

Sayı Issue :37

\title{
Knowledge Sharing Fear Among Public And Private Sector Employees
}

\begin{abstract}
The most valuable asset of today's businesses is their core competencies based on knowledge. Despite the considerable research on how to increase knowledge sharing in organizations, there is only a limited number of studies on knowledge hiding. No Turkish study has been found in google academic for December 2020 including "knowledge sharing fear" that expresses the perception that the employee will lose his/her original value if he/she shares his/her knowledge. This study aims to introduce knowledge sharing fear concept to Turkish literature and to investigate whether knowledge sharing fear differs according to gender and position in public or private sectors based on psychological ownership theory. Research hypotheses were tested using the knowledge sharing fear scale developed by Renzl (2008) with data gathered from 225 male and 158 female white-collar employees. According to psychological ownership theory, employees identify their identity through what they have by connecting more to what they spend energy and time on. In this study, the assumption that there was no difference in knowledge sharing fear by gender was supported. With $2 * 2$ factorial analysis, sectors as public and private, in addition to the position as manager and employee were evaluated. It has been found that knowledge sharing fear in those who are in managerial positions in the private sector is statistically significant and higher than other groups.
\end{abstract}

Keywords: Knowledge sharing fear, 2*2 factorial design, white-collar employees. 


\section{Giriş}

Hem ülke ekonomileri hem de işletmeler açısından, çalışanlar arasında bilgi paylaşımının en üst düzeyde olması istenmektedir. Çünkü günümüz işletmelerinin en değerli varlıkları bilgiye dayanan öz yetkinlikleridir. Bu nedenle akademik çalışmalarda da bilgi paylaşımının nasıl arttırılabileceği ele alınmıştır (Göksel, Aydıntan ve Bingöl, 2010; Ipe, 2003; Razmerita, Kirchner ve Nielsen, 2016; Şentürk ve Carman, 2019). Bilgi paylaşma sürecini etkileyen faktörler arasında örgüt kültürü (Gurteen, 1999), bilgi paylaşımının ödüllendirilmesi (Tohidinia ve Mosakhani, 2010), taraflar arasındaki bilgi farklılığ düzeyi (Wendling, Oliveira ve Carlos Gastaud Maçada, 2013), örgütsel adalet (Dirik, 2019; Lin, 2007; Şentürk ve Carman, 2019), örgütsel iletişimin niteliği ve sıklığ1 (Monteiro, Arvidsson ve Birkinshaw, 2008), mesleki bağlllık ve özyeterlilik (Çetin, Erenler ve Şentürk, 2016) sayılmaktadır. Görüldüğü üzere bilgi paylaşımının nasıl arttırılabileceğine yönelik araştırmalar fazla olmasına rağmen, bilgi saklamaya yönelik yeterince çalı̧̧ma yapılmadığ1 belirtilmektedir (Dirik, 2019; Riege, 2005; Witherspoon, Bergner, Cockrell ve Stone, 2013).

2004 yılında yapılan bir araştırmaya göre bilgi saklamanın Fortune 500 şirketlerine yıllık maliyeti 31,5 milyon dolardır (Babcock, 2004). Bilgi saklamanın öncüllerinden olan bilgi paylaşma korkusu, çalışanın bilgisini paylaştığı takdirde özgün değerini kaybedeceğine yönelik algısıdır (Renzl, 2008). Bilgi paylaşma korkusu, farklı nedenlerle ortaya çıkabilir. Öncelikle bilgisini paylaşan, paylaştığı iş arkadaşının kendisine rakip olmasına neden olabilir (Butt, 2019). Daha da önemlisi çalışan bilgisini paylaştığı için işini kaybetmeye yönelik korku geliştirebilir ve bu korkuda haklılık payı bulunabilir (Butt, 2019; Jha ve Varkkey, 2018; Navimipour ve Charband, 2016). Olumsuz bir örgüt ikliminde, çalışanlar paylaştıkları bilginin karşılığını alamayacakları yönünde korku geliştirebilirler (Huo, Cai, Luo, Men ve Jia, 2016).

Aralık 2020 itibariyle Google akademik üzerinden "bilgi paylaşma korkusu" anahtar kelimeleriyle yapılan aramada hiçbir sonuç bulunamamıştır. $\mathrm{Bu}$ nedenle bilgi paylaşma korkusunun Türkçe alanyazında incelenmesinin katkı sağlayacağ1 düşünülmektedir. Bilgi paylaşma korkusunun teorik çerçevesinin irdelenmesi, psikoloji, yönetim ve organizasyon gibi farklı alanlardaki bilim insanlarının ortak çalışmalarına zemin hazırlayabilir. Ayrıca beş sorudan oluşan bilgi paylaşma korkusu ölçeğinin bilgi yoğun işletme- 
lerde kullanılması, bu konudaki sorunların tespit edilip giderilmesinde yardımcı olabilir. Cornell Üniversitesi 2019 küresel inovasyon raporuna göre Türkiye inovasyon konusunda düşük performans gösteren ülkeler kategorisindedir (Global innovation index 2019). Bilgi paylaşma korkusunun azaltılarak bilgi paylaşımının arttırılması, işletmelerin doğrudan teknolojik yeteneklerinin ve karlılıklarının arttırılması anlamına gelir.

$\mathrm{Bu}$ araştırmada öncelikle bilgi paylaşma korkusu kavramı Türkçe alanyazına tanitılacak ve ilgili kavramlar incelenecektir. Bilgi paylaşma korkusunun, bireyin sahip olduğu bilgiye dayandığı göz önüne alındığında psikolojik sahiplik teorisi, zengin bir altyapı sunmaktadır. Psikolojik sahiplik teorisine göre sahiplik hissi insanın doğal bir duygusu olup (Yeşil, Bancar ve Budak, 2015, s. 61) sahiplik hissi ev, araba gibi maddi unsurlarda ortaya çıkabileceği gibi fikirlere, sanat eserlerine, hatta diğer insanlara yönelebilir (Pierce, Kostova ve Dirks, 2001). Bilgi paylaşma korkusunun bireysel özelliklere göre farklılaştı̆̆ ifade edilmekle birlikte (Atalay ve Özler, 2013; Butt ve Ahmad, 2019; Köseoğlu, Gider ve Ocak, 2011; Lachman ve Weaver, 1998; Ozler, Yilmaz ve Ozler, 2008) bilgi paylaşma korkusuna çok yakın bir kavram olan örgütsel sessizlik konusunda Türkiye'de yapılan alanyazın taramasında, cinsiyete göre tutarlı bulguların olmadığı belirtilmiştir (Yeşilaydın ve Bayın, 2015). Ayrıca yönetici pozisyonunda olmak ve iş kaybetme korkusunun bilgi paylaşma korkusunu tetikleyebileceği iddia edilmektedir (Butt, 2019; Jha ve Varkkey, 2018; Serenko ve Bontis, 2016). Alanyazındaki çalışmalardan ve psikolojik sahiplik teorisinden hareketle bu araştırmanın amaçları şu şekilde belirlenmiştir:

1. Bilgi paylaşma korkusunun ve ilgili kavramların Türkçe alanyazına tanitilmasi

2. Psikolojik sahiplik teorisini temel alarak çalışanların bilgi paylaşma korkusunda cinsiyete göre farklılık olup olmadığının sınanması

3. Psikolojik sahiplik teorisini temel alarak kamu ve özel sektörde yönetici olup olmamaya göre bilgi paylaşma korkusunda farklılık bulunup bulunmadığının incelenmesidir.

\section{Bilgi Paylaşma Korkusu ve İlgili Kavramlar}

Bilgi paylaşma korkusu, çalışanın bilgisini paylaştığı takdirde, özgün değerini kaybedeceğine yönelik korkusudur (Renzl, 2008). Bilgi paylaşma korku- 
su, bilgi saklama davranışının öncüllerindendir (Razmerita vd., 2016). Bilgi paylaşma korkusunu, yönetim ve organizasyon bağlamında tartışmadan önce, korku kavramı üzerinde durmak gerekir. Korku, hayatımızı şekillendiren en temel duygulardan biridir. Öyle ki modern toplum hayatında, bireyin çok farklı kaynaklardan gelen uyarıcılardan, fiziksel ve ruhsal sağlığına yönelik yoğun tehdit algılaması yaşadığı iddia edilmektedir (KishGephart, Detert, Treviño ve Edmondson, 2009). Korku durumunda birey, durum değerlendirmesi yapar, bu da zihinsel süreçlerin kullanılması anlamına gelir. Değerlendirme sonucunda ise durumla ilgili bir karara varılır (Rogers, 1975). Öfke duygusunun hâkimiyetinde, riskler iyimser bir şekilde değerlendirilirken, korkuda riskler sistematik bir şekilde değerlendirilerek azaltılmaya çalışılır. Bir diğer anlatımla korku durumunda birey, kendisi için ortaya çıkabilecek tehditleri ve riskleri azaltmaya odaklanır (Kligyte, Connelly, Thiel ve Devenport, 2013, s. 299). Korku duygusunun temel özelliği bireyi kaçınmacı savunma davranışına ve kaçmaya motive etmesidir (Öhman ve Mineka, 2001). Korku, diğer duygu durumlarından, refleksler ve sabit eylem kalıplarından farklı olarak devamlılık, öğrenme, derecelendirilebilirlik ve genellenebilirlik gibi çeşitli işlevsel özelliklere sahiptir (Mobbs vd., 2019).

Bilgi paylaşma korkusunda da çalışanlar, sahip oldukları bilgiyi diğer çalışanlarla farklı nedenlerle paylaşmaya korkarlar. Bilen çalışanın bilgisini bilmeyenlerle paylaşması aynı zamanda ikilem de oluşturmaktadır. Çünkü çalışana değer katan bilginin başkalarına verilmesi, bilgiyi alan açısından bir süre sonra bilgiyi verenin değersizleşmesi anlamına gelebilmektedir. $\mathrm{Bu}$ durum alanyazında insanın sosyal bir varlık olmasıyla açılanmaktadır. Eğer birey dayanışmanın zorunlu olduğu toplumsal düzende kaybetmekten korkarsa, bilgisini paylaşmayacaktır (Butt ve Ahmad, 2019). Eğer toplumsal alanda adil bir sosyal düzen tesis edilirse, birey paylaştı̆̆ bilgi nedeniyle gelecekte zarar görmeyeceğini düşünür, adil davranılacağını bilir ve bilgisini paylaşmaktan korkmaz (Renzl, 2008). Nitekim Türkçe alanyazında, örgütsel adalet algısının bilmezden gelme şeklindeki bilgi saklama davranışıyla ters yönde ilişkili olduğu ifade edilmektedir (Dirik, 2019).

Bilgi paylaşma korkusunu açıklamaya yönelik girişimler, genellikle fen bilimleri ve psikoloji alanında yapılan araştırmalara dayanmaktadır. Evrim teorisindeki bencil gen modeline göre bireyler kendi genlerinin devamlılığ1nı sağlayabilmek için temelde bencil davranırlar. Bu bakış açısıyla çalışanlar, 
toplumsal iyiden ya da örgütsel başarıdan ziyade bireysel başarılarını ön plana aldıkları için bilgiyi paylaşmaktan korkacaklardır. Dolayısıyla bilgi, ancak ekonomik çıkar söz konusuysa veya evrimsel bakış açısıyla bireye üstünlük sağlayacaksa paylaşlacaktır (Witherspoon vd., 2013, s. 269) .

Bilgi paylaşma korkusu kültürden kültüre farklılık göstermektedir. Danimarka'da 114 kobi çalışanı üzerinde yapılan bir araştırmaya göre çalışanların sadece $\% 6$ 'sı bilgilerinin kötüye kullanılacağından, \%4,3'ü bilgiyi paylaşırlarsa yerlerini bir başkasının alacağından endişe etmektedir (Razmerita vd., 2016). Diğer yandan Arnavutluk' ta gerçekleştirilen bir başka araştırmada yöneticilerin \%60'ının bilgiyi paylaşmaktan korktukları, bu durumun temel nedenleri arasında ulusal kültür olduğu bulgulanmıştır. Yine aynı çalışmada katılımcıların \%45'i bilgi paylaşma korkularının nedeni olarak iş pozisyonlarını kaybetmeyi göstermişlerdir (Vajjhala ve Baghurst, 2014).

Psikoloji alanındaki yaklaşımlara ve örgüt bilimine göre korku salt olumsuz bir duygu değildir (Keegan, 2015). Korku genellikle olumsuz bir duygu şeklinde algılansa da, aslında insanın varlığını koruması için gerekli temel duygular arasında yer alır. Örneğin sonucunu düşünmeden tehlikeli bir şekilde birden trafiğin yoğun olduğu bir yola koşan çocuk, davranışının olası sonuçları hakkında yeteri kadar bilgi sahibi olmadığı için korkmaz. Benzer şekilde korkularına rağmen, bir görevi başaran biri de duygularını yönetebildiği için egemenlik ve mutluluk duyguları yaşayacaktır (Bantinaki, 2012). Bu durum aslında bilgi saklama davranışı ile bilgi saklama korkusu arasındaki ilişkiyi de açıklamaktadır. Bilgi saklama (knowledge hiding), başka biri tarafından talep edilen bilginin gizlenmesini, bireyin sahip olduğu bilgiyi saklamaya veya saklamaya yönelik kasıtlı girişimi olarak tanımlanmaktadır (Connelly, Zweig, Webster ve Trougakos, 2012, s. 65). Bilgi saklama davranışı, bilgi paylaşma korkusu sonucu gerçekleşebilir, bu durumda kaçınmacı savunma stratejisi söz konusudur (Fang, 2017). Bilgi saklama davranışları arasında susma, sorulan sorulara baştan savma cevaplar verme, aptalı oynama, akılcı görünen açıklamalar yapma anlamına gelen rasyonalize saklama yer almaktadır (Demirkasimoglu, 2016). Bilgi saklama, çalışanın hatayla veya bilmediği için bilgisini paylaşmadığı durumları kapsamaz (Connelly vd., 2012). Üretkenlik karşıtı işyeri davranışlarından farklı olarak, bilgi saklama her zaman bir başka çalışana veya organizasyona zarar verme amaciyla yapılmaz. Aslında bilgi saklama, belirli bir duruma verilen genel bir tepkidir (Connelly ve Zweig, 2015, s. 480). Bilgi paylaşma korkusu 
her zaman bilgi saklama davranışına dönüşmeyebilir. Aynı durum tam tersi için de söylenebilir. Bilgisini paylaşmayan birinin davranışının tek nedeni bilgi paylaşma korkusu olmayabilir.

Bilgi paylaşma korkusu ile birlikte anılan bir diğer kavram bilgi paylaşmadır. Bilgi paylaşımı, çalışanların yeni bilgiler yaratmak için zımni ve açık bilgilerini karşılıklı olarak değiştirmeleri sürecidir (Razmerita vd., 2016). Bilgi paylaşımında birey kendi fikirleriyle bir sorunun daha iyi anlaşılabilmesi için başkasına rehberlik eder (McDermott, 1999, s. 107). Her ne kadar bilgi paylaşma ve bilgi saklama iki alternatif davranış seçeneği olarak düşünülse de iki kavram birbirinin zıttı değildir (Connelly vd., 2012). Bilgi paylaşma ile bilgi saklamanın motivasyon faktörleri farklıdır. Gagné vd. (2019) bilişsel iş gerekleri ve otonominin bilgi paylaşmanın sıklı̆̆ını arttırdığını, karşılıklı görev bağımlılı̆̆ının ise bilgi saklama düzeyini arttırdığını bulmuştur.

Bilgi saklamanın ön koşulları arasında güvensizlik sayılmaktadır (Renzl, 2008). Her ne kadar alanyazında örgüt içi güveni arttırmaya yönelik çabalardan ve önlemlerden bahsedilse de, bir tutum olarak bilgi paylaşma korkusunun oluşması hayatın başka alanlarında ve zamanlarında kazanılmış deneyimlerin sonucu olarak da gelişmiş olabilir (Kish-Gephart vd., 2009). Örneğin okul yıllarında bir konudaki bilgisini paylaştığı için dışlanan bir çalışan, iş hayatında da benzer süreçlere daha duyarlı hale gelebilir. Aynı zamanda bilgi paylaşımına yönelik olumsuz geleneksel yaklaşımlar da bilgi paylaşma korkusunun gelişmesine neden olabilir (Navimipour ve Charband, 2016).

\section{Bilgi Paylaşma Korkusu ve Psikolojik Sahiplik Teorisi}

Bilgi, deneyim ve uygulama ile öğrenilen bir dizi kural, prosedür ve işlemle özümsenmiş verinin örgütlenmiş bileşimidir (Bhatt, 2001, s. 70). McElroy (1999, s. 5)'a göre bilgi dünya, güzellik ve doğru hakkında varsayımların zihinsel ve sözel formülasyonudur. Bilgi; deneyim, değerler ve uzman bilgisinin bir araya getirilmesi ile anlam oluşturma sürecidir. Bilgi, bilenlerin zihninde oluşur ve uygulamaya aktarılır (Nonaka ve Toyama, 2015). Örgütlerde bilgi sadece örgütsel dokümanlarda saklanmaz aynı zamanda örgütsel rutinlerle, süreçlerle ve normlarla iç içe geçmiştir (Davenport ve Prusak, 1998, s.4). Bilginin insana, ihtiyaçlara ve algılamalara bağlı bir süreç olduğu 
göz önüne alındığında da, bilgi paylaşma korkusunun sübjektif bir kavram olarak değerlendirilmesi gerekir. Dolayısıyla bu araştırmada karşılıklı ilişkileri vurgulayan sosyal değişim teorisi yerine, bireyi temele alan psikolojik sahiplik teorisi (Liu, Wang, Hui ve Lee, 2012) kullanılmıştır.

Bilgi saklama konusunda psikolojik sahiplik teorisinin zengin bir altyapı sunduğu ifade edilmektedir (Fang, 2017). Psikolojik sahiplik teorisi felsefe, psikoloji gibi farklı bilim dallarından beslenir ve sahip olmanın insan psikolojisindeki önemine vurgu yapar. Hatta insanın "ben" anlayışının "benim" anlayışıyla bütünleştiğini ifade eder (Pierce vd., 2001, s. 299). Ellis (1985)' in alanyazın taraması sonuçlarına göre sahiplenici davranış, bireyin kendini ve kişisel alanını kapsayacak şekilde, tüm toplumlarda evrensel olarak mevcuttur. İnsan bilerek veya bilmeyerek, isteyerek veya istemeyerek sahip olduklarını benliğinin bir parçası haline getirir (Belk, 1988, s. 139). Bu bağlamda psikolojik sahiplik, bireylerin bir zihin durumu olarak sahiplik hedefini (maddi veya maddi olmayan) ya da onun bir parçasını "kendilerininmiş" gibi hissetmeleridir (Pierce vd., 2001, s. 299). Yönetim ve organizasyon bakış açısıyla psikolojik sahiplik, bir çalışanın hedefe karşı sahiplenici duygular geliştirdiği psikolojik temelde deneyimlenen bir olgudur (Van Dyne ve Pierce, 2004). Kisaca psikolojik sahiplik, "benim olan ne?" sorusuna verilen cevaptır (Olckers ve Du Plessis, 2012, s. 4). Psikolojik sahipliğin hem bilişsel hem de duygusal yönü vardır. Bireyin sahip olunanla ilgili farkındalığını, düşüncelerini, inançlarını ve duygularını yansıtır (Jussila, Tarkiainen, Sarstedt ve Hair, 2015, s. 123).

Psikolojik sahiplik, birbirleriyle ilişkili üç faktörle ortaya çıkmaktadır. Bunlar hedef üzerinde kontrol, hedefi yakından tanıma ve hedefe yatırım yapmadır (Pierce vd.., 2001; Pierce, Kostova ve Dirks, 2003). Hedef üzerinde kontrol faktörüne göre çalışanların yetkin ve ilişkilerinde etkin olmaya yönelik ihtiyacı, onları çevrelerini kontrol etmeye yöneltir. Hedefi yakından tanımaya göre psikolojik sahiplik, öz kimlik algısıyla ilişkilidir, bireyler sahip olduklarını yakından tanır ve onlar üzerinden çevresiyle etkileşime geçer. Hedefe yatırım yapma, bireylerin duygusal açıdan yatırım yaptıkları şeylere daha çok bağlanarak, mekân ve zamanda adeta kendilerini sabitleyebilecekleri bir yere sahip olduklarını ifade eder (Brown, Pierce ve Crossley, 2014, s. 320).

Psikolojik sahiplik perspektifiyle bilgi paylaşma korkusu ele alındığında, çalışanların kendi bilgileri üzerinde-eğer bilgi zımni bilgi ise-neredeyse ta- 
ma yakın kontrole sahip oldukları söylenebilir. Çünkü veri işlenmemiş olguları temsil ederken, veriyi işleyerek anlamlı bir hale yani bilgiye dönüştüren insandır (Nonaka ve Toyama, 2015). Örgütler için değerli bilgi, çalışanlar tarafından genellikle başkalarınca kopya edilemeyecek şekilde teknoloji, bireysel bilgi, etkileşim, kültür gibi farklı unsurların bir araya gelmesiyle oluşturulur (Bhatt, 2001). Dolayısıyla çalışanın, işyerinde ona yetkinlik ve ilişkilerinde etkinlik sağlama potansiyeli olan bilgisini paylaşmaktan korkması, onun etkinlik ihtiyacindan kaynaklanabilir.

Dittmar (1989) kadınlarla erkeklere sahip oldukları en önemli beş şeyi s1ralamalarını ve niçin önemli olduklarını açıklamalarını istemiş ve cinsiyetler açısından sahip olunana verilen önem itibariyle farklılık olmadığını bulgulamıştır. Bu da psikolojik sahiplik duygusu açısından kadınlar ve erkeklerin farklı olmadığına; ancak atfettikleri anlamın farklılaştığına işaret etmektedir. Bilgi paylaşma korkusuna yakın bir kavram olan örgütsel sessizlik konusunda alanyazın taraması yapan Yeşilaydın ve Bayın (2015), örgütsel sessizlik davranışında cinsiyete göre tutarlı bulguların olmadığını belirtmiştir. Demirkasimoglu (2016) bilgi saklama davranışı, Köseoğlu vd. (2011) da bilgi paylaşmayı engelleyen unsurlar açısından cinsiyetler arasında farklılık olmadığını bulgulamıştır. Alanyazında cinsiyet değişkenini kontrol değişkeni olarak inceleyen çalı̧malar (Connelly vd., 2012; Peng, 2013; Siemsen, Roth, Balasubramanian ve Anand, 2009) bilgi saklama davranışı açısından cinsiyetler arasında fark olmadığını ifade etmektedir. Ancak bilgi paylaşma davranışını inceleyen araştırmalarda özellikle kolektivist toplumlarda cinsiyet değişkeninin sorgulanması gerektiği belirtilmektedir (Ardichvili, Maurer, Li, Wentling ve Stuedemann, 2006; Navimipour ve Charband, 2016; Riege, 2005). Türk toplumunun kolektivist ve yüksek güç mesafesine sahip olması (Hofstede, 1984), alanyazında birbirleriyle çelişen sonuçların bulunması nedeniyle bilgi paylaşma korkusunda cinsiyete göre farklılık olup olmad1ğının sorgulanması gerekmektedir. Korkunun ve psikolojik sahipliğin cinsiyetten bağımsız olduğu göz önüne alınarak aşağıdaki hipotez geliştirilmiştir:

- H1: Bilgi paylaşma korkusu, cinsiyete göre farklılaşmamaktadır.

Psikolojik sahiplik teorisine göre bireyler duygusal açıdan yatırım yaptıkları şeylere daha çok bağlanırlar (Brown vd., 2014, s. 320). Söz konusu kişisel yatırım, zaman, fikirler, yetenekler, fiziksel, psikolojik ve entelektüel enerji gibi pek çok farklı şekilde gerçekleşebilir (Jussila vd., 2015). En belir- 
gin ve belki de en güçlü anlamda yapılan yatırım, bireyin o "şey" $i$ yaratmasıdır. Yaratma, onu yaratanın zamanını, enerjisini ve hatta değerlerini ve kimliğini kapsar. "Şeyler" onları yaratan kişiye iliştirilir, çünkü kendi varlıklarını ve biçimlerini bireyin çabalarına borçludur; bu nedenle, onları yaratan birey, ayn kendine sahip olduğu gibi onlara da sahip olur (Durkheim, 1957' den aktaran Pierce vd., 2001). Özellikle bilgi alanında çalışanların temel amacı da bilginin yaratılması, dağıtılması ve/veya uygulanmasıdır (Davenport ve Prusak,1998; Nonaka ve Toyama, 2015). Genel anlamda bakıldığında da çalışanların yaşamları üzerindeki kontrol ve daha büyük amaçlarla bağ kurma ihtiyaçlarını, meslek ve mesleki rolleri üzerinden yaptıkları bulunmuştur (Ikiugu vd., 2012).

Mesleğe ve mesleki rollere yapılan yatırım nitelik ve nicelik açısından arttıkça sahiplik ve kontrol duygusu da artmaktadır. Amerika'da 3.032 yetişkin üzerinde yapılan bir araştırmada örneklem genç, orta ve ileri yaş olmak üzere üçe ayrılmış, ileri yaşta olanların işyerindeki kontrol duygusunun diğer gruplarınkinden fazla olduğu ortaya çıkmıştır (Lachman ve Weaver, 1998). Bilginin çalışanlar, örgüt ve çevre arasındaki dinamik ilişkilere dayanılarak bireyin zihninde yaratıldı̆̆ (Nonaka ve Toyama, 2015) göz önüne alındığında, bu sürece ayrılan zamanın artmasıyla, çalışan ve bilgi arasındaki sahiplik ilişkisinin de artması beklenir. Yapılan araştırmalar da psikolojik sahipliğin yaşla beraber arttı̆̆ını göstermektedir (Atalay ve Özler, 2013; Ozler vd., 2008). Yönetici pozisyonunda olanların genellikle tecrübeli çalışanlar arasından seçildiği, bunun da yaşla doğrudan bağlantısı göz önüne alındığında, yönetici pozisyonundakilerin bilgi paylaşma korkusunun artması beklenebilir.

Örgütlerde hem astlar hem üstler sahip oldukları bilgi üzerinden kontrol sahibi olmaya çalışırlar, bu nedenle de bilgilerini örgütsel bilgi sistemine yükleme konusunda direnç gösterirler (Gray, 2001). Birleşik Arap Emirlikleri'nde yapılan bir araştırmaya göre yöneticilerin bilgi saklama nedenleri arasında astları üzerinde kontrolü kaybetmeme isteği gelmektedir (Butt ve Ahmad, 2019). Bilgi saklama davranışı hiyerarşik karşılıklı ilişkilerde görülmekle beraber, çalışanlar pozisyonlarına bağlı olarak bilgi paylaşmaktan korkabilirler. Çünkü yönetme isteği insanın en temel istekleri arasında gelmektedir ve yöneticiler nispeten avantajlı konumlarını koruma arzuları nedeniyle bilgi paylaşmaktan korkabilirler (Liu, Zhu Julie ve Lam Long, 2020). Psikolojik sahiplik teorisi açısından ise benlik tanımı "yönetici" po- 
zisyonu üzerinden yapıldığında, yöneticilik konumu, işin bir parçası olmaktan öte benliklerine yönelik tehdit algılamasına yol açabilir. Nitekim istismarcı yöneticilerin astlarının bilgi saklamaya yöneldikleri belirtilmektedir (Pradhan, Srivastava ve Mishra Dharmesh, 2019).

Özellikle yüksek düzeyde güç mesafesinin ve kolektivizmin geçerli olduğu ülkelerde, yöneticiler belirsizlik durumunda veya bilmedikleri konularda astlarına danışmamakta, bazı durumlarda astlarını potansiyel rakipler olarak değerlendirebilmektedir (Ghosh, 2011). Diğer taraftan bilgi yönetimi bileşenlerini kamu ve özel sektörde inceleyen McAdam ve Reid (2000) kamu sektörünün karlılıktan önce insanı daha fazla merkeze alması nedeniyle kamunun özel sektörle karşılaştııldığında informel bilgi yönetim süreçlerini daha etkin kullandığını bulgulamışlardır. Her ne kadar bilgi yönetiminde özel sektör, kamu ile karşılaştırıldığında pek çok açıdan daha başarılı olsa da (Chawla ve Joshi, 2010), etkin ve doğru bilginin paylaşımı güvene dayalı sosyal ağlarla gerçekleşmektedir. Xerox firması da yararlı ve etkin bilginin sosyal ağlar yoluyla taşındığını bulmuştur (Powers, 1999). Ancak söz konusu sosyal ağlar içinde, özel sektörde çalışanlar işlerini kaybetme endişesiyle bilgilerini paylaşmaktan korkabilirler (Labafi, 2017). Çünkü kamuda çalışanlarında iş kaybı performanstan ve rekabetten ziyade kanunlarla belirlenmiş kurallar çerçevesinde gerçekleşirken özel sektörde ekonomik krizler, işletmenin yatırım kararları, diğer çalışanlar gibi pek çok faktör iş kaybına neden olabilmektedir. Nitekim Arnavutluk'ta yapılan bir araştırmaya göre çalışanların \%45'inin bilgi paylaşma korkusunun nedeni işteki pozisyonlarını kaybetmedir (Vajjhala ve Baghurst, 2014). Amerika'da akademisyenlerin bilgi saklama nedenleri arasında ticari kaygılar sayılmaktadır (Campbell vd., 2002). Karmaşık ve belirsizliğin yüksek olduğu ortamlarda bilgi saklama davranışı artmaktadır (Webster vd., 2008). Bu nedenle, özel sektörde yöneticilerin yetkin ve ilişkilerinde etkin olmaya yönelik ihtiyacını karşılamak ve konumlarını korumak amacıyla bilgi paylaşma korkusunu daha fazla yaşadıkları ileri sürülebilir. Dolayısıyla aşağıdaki hipotez oluşturulmuştur:

H2: Kamu ve özel sektörde yönetici olarak çalışıp çalışmamaya göre bilgi paylaşma korkusunda anlamlı düzeyde farklılık vardır. 


\section{Örneklem}

Araştırma 2018-2019 akademik yılında Adana Alpaslan Türkeş Bilim ve Teknoloji Üniversitesi'nde yönetim ve organizasyon tezsiz yüksek lisans programı öğrencilerinden ve onların iş çevresinden elde edilen verilerle gerçekleştirilmiştir. Bu nedenle araştırma verileri için etik onam çıkarılmamış, kolayda ve kartopu örnekleme yöntemleri kullanılmıştır. Verilerin toplanmasında yüz yüze anket yönteminden yararlanılmıştır. Öncelikle tezsiz yüksek lisans öğrencileri araştırmaya katılmış, bir kısmı ise araştırmaya destek olmak amaciyla basılmış anketleri alarak iş arkadaşlarına doldurtmuşlardır. Bu grubun örneklem olarak seçilmesinin nedeni öğrencilerin farklı sektörlerde bulunmalarının yanı sıra yönetici pozisyonunda çalışanlara ulaşmanın kolay olmasıdır. Aynı zamanda maliyet ve zamandan tasarruf sağlanmıştır. Örneklem büyüklüğü seçiminde kullanılan istatistiki analizlerin gereklilikleri göz önüne alınmıştır.

Araştırmaya 225 erkek (\%58,7), 158 kadın (\%41,3) katılmış olup, toplam örneklem sayısı 383'tür. Araştırmaya katılanların yaşı 18-60 yaş aralığındadır, yaş ortalamaları 34.88'dir ( $\mathrm{Ss}=7,96)$. Araştırma örnekleminde 86 yönetici (\%22,5), 297 çalışan $(\% 77,5)$ bulunmaktadır. Katılımcılar 1 ila 34 yıl arasında tecrübeye sahip olup, ortalama 8,29 yıl çalışmışlardır (SS=7,88).

\section{Veri toplama araci}

Bilgi paylaşma korkusunun, operasyonel tanımı çalışanın bilgisini paylaştığ takdirde özgün değerini kaybedeceğine yönelik algısı (Renzl, 2008) olarak kabul edilmiş ve Renzl (2008)'in çalışmasındaki beş ifade ile ölçülmüştür. Çalışmada ölçeğin Cronbach's Alpha katsayısı ,84 olarak raporlanmıştır. Anket formunda cinsiyet, sektör, pozisyon ve yaş bilgileri de yer almıştır.

\section{Verilerin Analizi ve Bulgular}

Bilgi paylaşma korkusuna ilişkin verilen ifadeler ile ortalama ve standart sapma değerleri Tablo 1'de sunulmaktadır. Çalışanların en çok $(X=2,13)$ iş arkadaşlarıyla işe ilişkin bildiğim her şeyi paylaşmam ifadesine katıldıkları görülmüştür. 
Tablo 1. Bilgi paylaşma korkusuna ilişkin ortalama ve standart sapma değerleri

\begin{tabular}{lll}
\hline Ölçek ifadeleri & X & \multicolumn{1}{l}{ SS } \\
\hline Eğer işimle ilgili bütün bildiklerimi herkesle paylaşırsam, benim yerime bir başkası geçebilir. & 1,93 & 1,15 \\
\hline Eğer işe ilişkin bütün bildiklerimi paylaşırsam, bundan hiçbir şey elde etmem. & 1,91 & 1,17 \\
\hline İş arkadaşlarımla işe ilişkin bildiğim her şeyi paylaşmam. & 2,13 & 1,35 \\
\hline Eğer işe ilişkin bilgilerimin hepsini paylaşırsam, işyerinde bilgi avantajimı kaybederim. & 1,95 & 1,15 \\
\hline Bilgiyi paylaşmak, güç kaybetmek demektir. & 1,77 & 1,10 \\
\hline Bilgi paylaşma korkusu (toplam) & 9,68 & 4,62 \\
\hline
\end{tabular}

Verilerin çarpıklık ve basıklık değerleri incelenmiş, tüm değerlerin kabul edilebilir düzeyde olduğu görülmüştür. "Bilgi paylaşma korkusu, cinsiyete göre farklılaşmamaktadır" hipotezi bağımsız örneklem T testi ile sınanmış ve hipotez desteklenmiştir (Bknz Tablo 2).

Tablo 2. Cinsiyete göre bilgi paylaşma korkusu bağımsız gruplar t testi sonuçları

\begin{tabular}{lllllll}
\hline Gruplar & $\mathbf{N}$ & $\mathbf{X}$ & SS & $\mathbf{t}$ & $\mathbf{d f}$ & $\mathbf{P}$ \\
\hline Erkek & 225 & 9,98 & 4,99 & 1,53 & 373,80 & \multirow{2}{*}{13} \\
\cline { 1 - 4 } Kadın & 158 & 9,27 & 4,02 & & & \\
\hline
\end{tabular}

“Kamu ve özel sektörde yönetici olarak çalışıp çalışmamaya göre bilgi paylaşma korkusunda anlamlı düzeyde farklılık vardır" hipotezini test etmek amaciyla parametrik 2x2 varyans analizi uygulanmıştır. Ancak faktöriyel varyans analizinin temel sayıltıları arasında örneklem büyüklüklerinin birbirine yakın olması gelmektedir; öyle ki faktör varyansları homojen olmasa bile her bir gruptaki örneklem sayısı büyük farklılık göstermediği sürece test istatistikleri doğru sonuçlar vermektedir (Boneau, 1960; Kaplan ve George, 1995). Faktöriyel desenlerde her bir faktöre tanımlı minimum örneklem büyüklüğüne dair farklı tavsiyeler sunulmaktadır. Her bir gruptaki örneklem sayısının en az 10 (Hox, 1998) veya 25 (Kotrlik ve Higgins, 2001; Snijders ve Bosker, 1993) olması gerektiği belirtilmektedir. Ancak çalışmada Tip 1 hatayı en aza indirebilmek ve güç analizi gereklilikleri de göz önüne alınarak her bir kategoride 40 örneklem hedefi seçilmiştir (Dziak, Nahum-Shani ve Collins, 2012; McNeish ve Stapleton, 2016). Faktöriyel desende çapraz tablolar incelenmiş ve en az örneklem sayısı özel sektörde yönetici pozisyonunda çalışanlar $(n=40)$ olduğundan, özel sektör-çalışan, kamu-çalışan örneklemlerinden SPSS üzerinden tamamen rastgele alt örneklem belirlenmiş ve örneklem temsili yaş üzerinden izlenmiştir. Örneklem büyüklüğü kriterinin sağlanması ve yaşa ilişkin değerlerin çok büyük 
sapma göstermemesi nedeniyle kamuda ve özel sektörde çalışan pozisyonunda olanlar alt örneklemler üzerinden analize dâhil edilmiştir. Alt örneklemlerin tamamen rastgele seçim kriteri yüzde üzerinden hedef sayıyı sağlayacak oranda hesaplanmış ve yaş değişkeninin ortalama ve standart sapma değerleri Tablo 3'te sunulmuştur. Alt gruplar ve tam veri setine gruplar itibariyle T testi yapılmış, ilgili değerler itibariyle alt örneklemin örneklemi temsil ettiğine karar verilmiştir.

Tablo 3. Özel ve kamuda çalışanlar ile alt örneklemlerdeki yaş değişkenine ilişkin veriler

\begin{tabular}{lllllll}
\hline & Alt örneklem & \multicolumn{5}{c}{ Orijinal veri } \\
& $\mathbf{N}$ & $\mathbf{X}$ & SS & N & X & SS \\
\hline Özel sektör-çalışan & $(\% 26) 42$ & 31 & 5.62 & 160 & 30.58 & 5.95 \\
\hline Kamu sektörü-çalş̧an & $(\% 29) 40$ & 35,20 & 8,92 & 137 & 36.04 & 7.93 \\
\hline
\end{tabular}

Alt örneklemde verilerin dağılımı Shapiro Wilk testi ile sınanmıştır. Bilgi paylaşma korkusunun sektör ve pozisyon göz önüne alındığında $(\mathrm{D}(40)=.96, \mathrm{p}=.15)$ normal dağılıma uygun olduğu saptanmıştır. Pozisyon değişkeni yönetici ve çalışan, sektör ise özel ve kamu olmak üzere iki düzeyde incelenmiştir. Pozisyon hariç olmak üzere tüm etkiler \%95 güven aralığında anlamlı bulunmuştur. Sektör faktörü için temel etki $F(1,168)=8,4$ p<.005 düzeyindedir. Özel sektörde çalışanlar $(X=10,70, S S=4,48)$ kamuda çalışanlara $(X=8,86, S S=3,86)$ göre daha yüksek düzeyde bilgi paylaşma korkusu yaşamaktadır. Bilgi paylaşma korkusunda pozisyon faktörünün temel etkisi anlamlı bulunmamıştır, $\mathrm{F}(1,168)=1.00, \mathrm{p}=, 32$. Bilgi paylaşma korkusu yöneticilerde $(X=10,01, S S=3,99)$ ve çalışanlarda $(X=9,50, S S=4,54)$ birbirine benzemektedir. Sektör ve pozisyona bağlı olarak anlamlı etkileşim etkisi bulunmuştur, $F(1,168)=6,71, p=, 01$. Özel sektörde yönetici olanların bilgi paylaşma korkusu $(X=11,88, S S=4,05)$ istatistiksel açıdan anlamlı derecede yüksektir (Bknz Tablo 4). 
Tablo 4. Pozisyon ve sektöre göre bilgi paylaşma korkusuna dair 2*2 faktöriyel ANOVA sonuçları

\begin{tabular}{llllll}
\hline Varyans Kaynağı & $\begin{array}{l}\text { Karelerin } \\
\text { Toplamı }\end{array}$ & Sd & $\begin{array}{l}\text { Karelerin } \\
\text { ortalaması }\end{array}$ & F & $\begin{array}{l}\text { Anlamlılık } \\
\text { düzeyi }\end{array}$ \\
\hline Pozisyon & 16,99 & 1 & 16,91 & 1,01 &, 32 \\
\hline Sektör & 141,65 & 1 & 141,65 & 8,40 &, 00 \\
\hline Pozisyon*Sektör & 113,18 & 1 & 113,18 & 6,71 &, 01 \\
\hline Hata & 2767,05 & 164 & 16,87 & & \\
\hline Toplam & 19048 & 168 & & & \\
\hline
\end{tabular}

Etki boyu büyüklügüunü değerlendirebilmek amacıyla kısmi eta kare değerine $\left(\eta_{p}^{2}\right)$ bakılmıştır. Kısmi eta-kare değeri sektör için 0,09; sektör ve pozisyon için 0,07 olarak hesaplanmıştır. Bu değere göre bilgi paylaşma korkusundaki varyansın \%9'u sektör, \%7,1'i sektör ve pozisyon değişkeni tarafından açıklanmaktadır. Her ne kadar varyans itibariyle ilgili rakamlar zayıf olsa da istatistiki anlamlılık açısından değerlendirildiğinde $\mathrm{H} 2$ hipotezi desteklenmiştir.

\section{Sonuç ve Öneriler}

Bu çalışmada bilgi paylaşma korkusu ve ilgili kavramlar Türkçe alanyazına tanıtılmıştır. Psikolojik sahiplik teorisini temel alarak çalışanların bilgi paylaşma korkusunda cinsiyete, kamu ve özel sektörde yönetici olma durumuna göre farklılık olup olmadığı araştırılmıştır. Beklendiği üzere bilgi paylaşma korkusunda cinsiyete göre farklılık bulunmamıştır. Yine beklendiği üzere özel sektörde yönetici pozisyonunda bulunanların bilgi paylaşma korkusu düzeyinin yüksek olduğu saptanmıştır.

Bilgi paylaşma korkusu, çalışanın bilgisini paylaştı̆̆ takdirde, özgün değerini kaybedeceğine yönelik korkusudur (Renzl, 2008). Çalışanların bilgi paylaşma korkusunu açıklamada psikolojik sahiplik teorisi zengin bir altyapi sunmaktadır (Fang, 2017). Bilgi tamamen bireyin zihninde kendisi tarafından oluşturulur (Nonaka ve Toyama, 2015), bu yönüyle de psikolojik sahiplik teorisinde anılan hedef üzerinde kontrol, hedefi yakından tanıma, hedefe yatırım yapma (Pierce vd., 2001; 2003) kavramlarıyla örtüşmektedir. 
Çalışan bilgisini özellikle de zımni bilgi ise paylaşma ya da paylaşmama konusunda tam bir kontrole sahiptir. Söz konusu bilgiyi oluşturabilmek için anlamaya ve bilgiyi ortaya koyabilmek için zamanını ve zihinsel enerjisini bilgiye yöneltmek durumundadır.

Bu araştırmada "Bilgi paylaşma korkusu, cinsiyete göre farklılaşmamaktadır" hipotezi desteklenmiştir. Cinsiyete göre bilgi paylaşma korkusunda farklılık olmaması, Yeşilaydın ve Bayın (2015), Demirkasimoglu (2016), Peng (2013), Connelly vd. (2012), Siemsen vd. (2009), Köseoğlu vd. (2011)'nin araştırma sonuçlarıyla tutarlılık göstermektedir. Kuramsal açıdan bakıldığında sahiplenici davranış, bireyin kendini ve kişisel alanını kapsayacak şekilde, tüm toplumlarda evrensel olarak mevcuttur (Belk, 1988; Ellis, 1985). Psikolojik sahiplik, bir zihin durumu olarak bireylerin "şeyleri" kendilerininmiş gibi hissetmesidir ki (Dittmar, 1989; Pierce vd., 2001) evrensel bir yönü bulunmaktadır. Bu durum, kültür ve toplumsal cinsiyet algılamalarındaki farklılıklara rağmen cinsiyetler arasında bilgi paylaşma korkusunda benzerliğe neden olabilir. Araştırma verilerinin beyaz yakalı çalışanlardan elde edildiği göz önüne alındığında, profesyonel iş değerlerinin varlığı, cinsiyetler arasındaki farklılıkları ortadan kaldıran bir diğer faktör olabilir. Bu nedenle bilgi paylaşmaya veya saklamaya ilişkin örgütsel uygulamalarda ve akademik çalışmalarda cinsiyetçi bakış açısının yanlış olacağı düşünülmektedir.

Mesleğe ve mesleki rollere yapılan yatırım nitelik ve nicelik açısından arttıkça sahiplik ve kontrol duygusu da artmaktadır (Lachman ve Weaver, 1998). Bu bağlamda oluşturulan "Kamu ve özel sektörde yönetici olarak çalışıp çalışmamaya göre bilgi paylaşma korkusunda anlamlı düzeyde farklılık vardır" şeklindeki hipotez desteklenmiştir. Özel sektörde yönetici olanların en yüksek düzeyde bilgi paylaşma korkusu yaşadıkları sonucuna varılmıştır. Söz konusu bulgu, çalışma ortamındaki rekabetin bilgi paylaşımının önünde engel olduğunu belirten Köseoğlu vd. (2011)'nin bulgularıyla paralellik göstermektedir. Aynı zamanda yüksek düzeyde güç mesafesinin geçerli olduğu ülkelerde yöneticiler, belirsizlik durumunda veya bilmedikleri konularda astlarına danışmamakta, hatta bazen astlarını kendi güçlerine rakip olabilecek adaylar şeklinde değerlendirebilmektedir (Ghosh, 2011). Dolayısıyla yüksek güç mesafesi, bilginin paylaşılmasına olanak sağlayan sağlıklı bir iletişim sürecinin önündeki bir engel olabileceği gibi iletişim eksikliği de yüksek güç mesafesi algılamasına neden olabilir (Güğerçin, 
2018,s. 91). Neticede iletişim eksikliği, bilgi saklama ve güç mesafesi ilişkisi bir sarmal halini alabilir. Bu noktadan hareketle astlar ve üstler arasındaki karşılıklı ilişkilerde iletişim eksikliği, güç mesafesi ve bilgi saklama değişkenlerini inceleyen çalışmaların alana katkı sağlayacağı düşünülmektedir.

Bilgi paylaşma korkusu sektör açısından değerlendirilirken, kamu çalışanlarında iş kaybının rekabetten bağımsız olarak kanunlarla belirlenmiş net kurallar çerçevesinde gerçekleştiği, özel sektörde ise ekonomik krizler, işletmenin yatırım kararları, diğer çalışanlar gibi pek çok faktörden etkilendiği dikkate alınmalıdır. Nitekim Arnavutluk'ta yapılan bir araştırmaya göre çalışanların \% 45 ' $\mathrm{i}$ bilgi paylaşma korkularının nedeni iş pozisyonlarını kaybetmeye dayanmaktadır (Vajjhala ve Baghurst, 2014). Bu nedenle, özel sektörde yöneticilerin yetkin ve ilişkilerinde etkin olmaya yönelik ihtiyacını karşılamak ve konumlarını korumak amacıyla bilgi paylaşma korkusunu daha fazla yaşadıkları düşünülmektedir.

$\mathrm{Bu}$ araştırmanın temel sınırlılıklarından biri kolayda örneklem yönteminin kullanılmasından kaynaklanmaktadır. Özel sektör ve kamu alanında çalışanlar alt sektörler itibariyle ele alınmamıştır. Oysa ne tüm kamu örgütleri ne de özel sektördeki örgütler sahip oldukları bilgi, bilginin doğası ve paylaşımı itibariyle aynı değildir. Örneğin bilgisayar yazılımı, genetik araştırmalar gibi yoğun bilgi gerektiren işletmelerle, fason imalat yapan tekstil işletmeleri bilgi paylaşma yoğunluğunda ve bilgi paylaşma korkusunda farklılaşacaklardır. İleride yapılacak olan çalışmalarda kamu ve özel sektör arasındaki farklılıkların ortaya konulmasında, benzer faaliyet alanlarındaki örgütlerin seçilmesi daha yararlı olabilir. Çalışmada her ne kadar özel sektör yöneticilerinin istatistiki açıdan anlamlı bir şekilde daha çok bilgi paylaşma korkusuna sahip oldukları bulgulanmış olsa da, açıklama düzeyi düşük kalmıştır. Bu durum bilgi paylaşma korkusunu daha iyi açıklayan başka değişkenlerin ve/veya sosyal beğenirlik kaygısıyla katılımcıların gerçek davranışlarıyla verdikleri cevaplar arasında farklılık olabileceğini düşündürmektedir. Nitekim ölçek ifadelerine verilen ortalama değerlerin düşük olduğu görülmektedir. Oysa Çin'de bilişim sektöründe çalışanlar arasında bilgi paylaşma korkusuna ilişkin ifadelerin ortalama değerlerin 2,68 ile 4,32 arasında değiştiği görülmektedir (Hsu, Chang, 2014). Bu nedenle gelecekte yapılacak çalışmalarda sosyal beğenirlik etkisinin dikkate alınması tavsiye edilmektedir. 
Araştırmaların genellikle etkin bilgi yönetim sistemlerine (Özdemirci, Aydın, 2007; Metin, 2020) ve bilgi paylaşımına odaklandığı görülmektedir (Göksel, Aydıntan ve Bingöl, 2010; Şentürk ve Carman, 2019). Ancak bilgi saklama ve bilgi paylaşmanın zıt değil farklı kavramlar olduğu göz önüne alındığında, bilgi saklama davranışının ve bilgi paylaşma korkusu gibi öncüllerinin araştırılmasının gerek alanyazına gerekse uygulayıcılara faydalı olacağ düşünülmektedir. Alanyazın incelendiğinde de bilgi paylaşma korkusuna ilişkin Türkçe çalışma olmadığı görülmüştür. Ayrıca bilgi paylaşma korkusunun öncülleri ve bu korkunun davranışa yansıması araştırılabilir. İşletmelerde bilgi paylaşma korkusunun ortaya çıkmasına neden olan bireysel ve örgütsel faktörlerin insan kaynakları bölümü tarafından ele alınmasıyla, etkin bilgi yönetim süreçlerinin kurulması da sağlanabilir. Bu süreçte kısa bilgi paylaşma korkusu ölçeği, başlangıç noktası olabilir. 


\title{
EXTENDED ABSTRACT
}

\section{Knowledge Sharing Fear Among Public And Private Sector Employees}

\author{
Bilge Aksay \\ Alpaslan Türkeş Science anda Technology University
}

Core competencies based on knowledge are the most valuable ones. Therefore, ways to increase knowledge sharing are discussed in academic studies (Göksel, Aydıntan, and Bingöl, 2010; Ipe, 2003; Razmerita, Kirchner, and Nielsen, 2016; Şentürk and Carman, 2019). Despite the considerable research on how to increase knowledge sharing in organizations, there is only a limited number of studies on knowledge hiding and its antecedents (Dirik, 2019; Riege, 2005; Witherspoon, Bergner, Cockrell, and Stone, 2013). To the best of the author's knowledge, no Turkish study has been found in Google Academic about "knowledge sharing fear", which is referred to as the perception that the employee will lose his/her original value if he/she shares his/her knowledge. Within the framework of psychological ownership theory, this study aims to introduce the concept of knowledge sharing fear to Turkish literature and to investigate whether knowledge sharing fear differs according to gender and position in public or private sectors.

According to psychological ownership theory, the feelings of ownership are natural for human beings (Green, Bancar, and Budak, 2015, p. 61) and can be related to material elements such as home, car, or even with abstract things such as ideas, works of art, even other people (Pierce, Kostova, and Dirks, 2001). Based on the studies in literature and psychological ownership theory, the objectives of this research were determined as follows:

1. To introduce knowledge sharing fear and related concepts to Turkish literature,

2. To analyze whether there is a gender difference in knowledge sharing fear,

3. To investigate whether there is a difference in knowledge sharing fear, according to hold an administrative position or not in the public and private sectors. 
Fear is one of the most fundamental emotions that shape our lives. In case of fear, the individual performs a situational assessment, which means the use of mental processes. As a result of the evaluation, a decision is made regarding the situation (Rogers, 1975). The main feature of the emotion is that it motivates the individual to exhibit defensive behavior (Öhman and Mineka, 2001).

According to Ellis's (1985) field review results, possessive behavior is universally available in all societies, covering the individual's self and personal space. Individuals intentionally or unintentionally make what they possess a part of themselves (Belk, 1988, p. 139). In this context, ownership arises when an individual feels the goal of ownership (material or intangible) or part of it as "his own" as a state of mind (Pierce et al., 2001, p. 299). Psychological ownership, in short, is the answer to the question "What is mine?" (Olckers \& Du Plessis, 2012, p. 4). It reflects the awareness, thoughts, beliefs, and feelings of the individual about what is possessed (Jussila, Tarkiainen, Sarstedt, \& Hair, 2015, p. 123). Psychological ownership, from the management and organization perspective, is a phenomenon experienced on a psychological basis in which an employee develops possessive feelings towards the target (Van Dyne and Pierce, 2004).

In knowledge sharing fear, employees hesitate to share their knowledge with other employees for different reasons. Sharing the knowledge with others also poses a dilemma. Because there emerges the risk of becoming worthless for the one who shares his/her knowledge in the eyes' of the knowledge receiver. If the individual is afraid of losing the power in which solidarity is mandatory, he will not share his knowledge (Butt and Ahmad, 2019). If a fair social order is established in the social sphere, the individual thinks that he/she will not be harmed in the future because of the knowledge he/she shares, knowing that he/she will be treated fairly in the future (Renzl, 2008). According to a study conducted in Denmark, only 6\% of employees were concerned that their knowledge would be misused, and $4.3 \%$ were worried that someone else would take their position if they had shared their knowledge (Razmerita et al., 2016). On the other hand, another study made in Albania found that $60 \%$ of managers were afraid to share their knowledge and national culture was stated among the main reasons for this high level of fear. In the same study, $45 \%$ of respondents referred to losing 
their job positions as the reason for their knowledge-sharing fear (Vaj)hala and Baghurst, 2014).

Despite no gender difference was reported on knowledge hiding (Connelly et al., 2012; Peng, 2013; Siemsen, Roth, Balasubramanian, andAnand, 2009) in individualist cultures still, there is a need for further research in collectivist cultures (Ardichvili, Maurer, Li, Wentling, and Stuedemann, 2006; Navimipour and Charband, 2016; Riege, 2005).

H1: Knowledge sharing fear does not differ by gender.

In high power distance and collectivist countries, managers do not consult their subordinates in case of uncertainty or on matters they do not have adequate knowledge, considering their subordinates as potential competitors (Ghosh, 2011).

$\mathrm{H} 2$ : There is a significant difference in knowledge sharing fear according to whether or not to be in an administrative position in the public and private sectors.

The research involved 225 men (58.7\%) and 158 women (41.3\%) and had a total sample of 383. The age range of the participants in the study was 1860 years, with an average age of $34.88(\mathrm{SD}=7.96)$. The research sample included 86 managers (22.5\%) and 297 employees (77.5\%). Participants' experience in years ranged from 1 to 34 with an average of 8.29 (SD=7.88). Knowledge sharing fear was measured by the scale developed by Renzl (2008).

"Knowledge sharing fear does not differ by gender" hypothesis was tested with an independent sample T-test, and it was supported.

Parametric $2 \times 2$ factorial variance analysis was conducted to test $\mathrm{H} 2$. Sample sizes were adjusted by random selection in SPSS. The position variable was examined at two levels: administrative position and nonadministrative position, and sector as private and public. All effects, excluding position, were found to be significant in the $95 \%$ confidence level. The main impact for the industry factor was $F(1,168)=8.4 p<.005$. Private sector employees $(\mathrm{M}=10.70, \mathrm{SD}=4.48)$ had a higher level of knowledge sharing fear than public employees $(\mathrm{M}=8.86, \mathrm{SD}=3.86)$. Similarly private sector executives' knowledge sharing fear $(\mathrm{M}=11.88, \mathrm{SD}=4.05)$ was statistically significantly higher than the other groups.

Although the study found that private sector managers had statistically significant higher level of knowledge sharing fear, the explanatory power remained low. This suggests that there may be other variables that better 
explain knowledge sharing fear and/or the discrepancy due to social desirability.

\section{Kaynakça / References}

Ardichvili, A., Maurer, M., Li, W., Wentling, T. ve Stuedemann, R. (2006). Cultural influences on knowledge sharing through online communities of practice. Journal of Knowledge Management, 10(1), 94-107. doi:10.1108/13673270610650139

Atalay, C. G. ve Özler, D. E. (2013). A Research to determine the relationship between organizational justice and psychological ownership among non-family employees in a family fusiness. Procedia - Social and Behavioral Sciences, 99, 247256. https://doi.org/10.1016/j.sbspro.2013.10.492

Babcock, P. (2004). Shedding light on knowledge management. HR Magazine, 49(5), 46-50. 16 Kasım 2020 tarihinde https://www.shrm.org/hr-today/news/hrmagazine/Pages/0504covstory.aspx adresinden erişildi.

Bantinaki, K. (2012). The paradox of horror: Fear as a positive emotion. The Journal of Aesthetics and Art Criticism, 70(4), 383-392. https://doi.org/10.1111/j.15406245.2012.01530.xBelk, R. W. (1988). Possessions and the extended self. Journal of Consumer Research, 15(2), 139-168. doi:10.1086/209154.

Bhatt, G. D. (2001). Knowledge management in organizations: examining the interaction between technologies, techniques, and people. Journal of Knowledge Management, 5(1), 68-75. https://doi.org/10.1108/13673270110384419

Boneau, C. A. (1960). The effects of violations of assumptions underlying the $t$ test. Psychological Bulletin, 57(1), 49-64. doi:10.1037/h0041412

Brown, G., Pierce, J. L.ve Crossley, C. (2014). Toward an understanding of the development of ownership feelings. Journal of Organizational Behavior, 35(3), 318338. https://doi.org/10.1002/job.1869

Butt, A. S. (2019). Determinants of top-down knowledge hiding in firms: an individual-level perspective. Asian business and management, 1-21. doi: 10.1057/s41291019-00091-1

Butt, A. S.ve Ahmad, A. B. (2019). Are there any antecedents of top-down knowledge hiding in firms? Evidence from the United Arab Emirates. Journal of knowledge Management. doi: 10.1108/JKM-04-2019-0204

Campbell, E. G., Clarridge, B. R., Gokhale, M., Birenbaum, L., Hilgartner, S., Holtzman, N. A. ve Blumenthal, D. (2002). Data withholding in academic genetics: evidence from a national survey. Jama, 287(4), 473-480. 
Chawla, D.ve Joshi, H. (2010). Knowledge management initiatives in Indian public and private sector organizations. Journal of Knowledge Management, 14(6), 811827. doi:10.1108/13673271011084871

Connelly, C. E.ve Zweig, D. (2015). How perpetrators and targets construe knowledge hiding in organizations. European Journal of Work and Organizational Psychology, 24(3), 479-489. doi:https://doi.org/10.1080/1359432X.2014.931325

Connelly, C. E., Zweig, D., Webster, J.ve Trougakos, J. P. (2012). Knowledge hiding in organizations. Journal of Organizational Behavior, 33(1), 64-88. doi:https://doi.org/10.1002/job.737

Çetin, A., Erenler, E.ve Şentürk, M. (2016). Mesleki bağlllık ve mesleki özyeterlik algısının bilgi paylaşma davranışına etkisi. Çankırı Karatekin Üniversitesi İktisadi ve Idari Bilimler Fakültesi Dergisi, 6(2), 289-316. https://dergipark.org.tr/en/download/article-file/382472 adresinden erişildi.

Davenport, T. H.ve Prusak, L. (1998). Working knowledge: How organizations manage what they know: England: Harvard Business Press.

Demirkasimoglu, N. (2016). Knowledge hiding in academia: Is personality a key factor? International Journal of Higher Education, 5(1), 128-140.11 Kasım 2020 tarhinde https://files.eric.ed.gov/fulltext/EJ1088661.pdf adresinden erişildi.

Dirik, D. (2019). Örgütsel adalet algısı ve bilgi saklama davranişi arasindaki ilişkillerde algilanan örgütsel politikanın rolü üzerine bir araştırma. Electronic Turkish Studies, 14(2), 296-312. doi:10.7827/TurkishStudies.14932S

Dittmar, H. (1989). Gender identity-related meanings of personal possessions. British Journal of Social Psychology, 28(2), 159-171. doi:https://doi.org/10.1111/j.20448309.1989.tb00857.x

Dziak, J. J., Nahum-Shani, I.ve Collins, L. M. (2012). Multilevel factorial experiments for developing behavioral interventions: Power, sample size, and resource $\begin{array}{llll}\text { considerations. } & \text { Psychological }\end{array}$ doi:https://doi.org/10.1037/a0026972

Ellis, L. (1985). On the rudiments of possessions and property. Social Science Information, 24(1), 113-143. doi:10.1177/053901885024001006

Fang, Y.-H. (2017). Coping with fear and guilt using mobile social networking applications: Knowledge hiding, loafing, and sharing. Telematics and Informatics, 34(5), 779-797. doi:https://doi.org/10.1016/j.tele.2017.03.002

Gagné, M., Tian, A. W., Soo, C., Zhang, B., Ho, K. S. B.ve Hosszu, K. (2019). Different motivations for knowledge sharing and hiding: The role of motivating work design. Journal of Organizational Behavior, 40(7), 783-799. doi:https://doi.org/10.1002/job.2364 
Ghosh, A. (2011). Power distance in organizational contexts-a review of collectivist cultures. Indian Journal of Industrial Relations, 47(1), 89-101. doi:https://www.jstor.org/stable/23070557

Global innovation index. (2019). 25 Aralk 2020 tarihinde https://www.globalinnovationindex.org/userfiles/file/reportpdf/GII2019keyfinding-E-Web3.pdf adresinden erişildi.

Göksel, A., Aydıntan, B.ve Bingöl, D. (2010). Örgütlerde bilgi paylaşma davranışı: Sosyal sermaye boyutundan bir bakış. Ankara Üniversitesi SBF Dergisi, 65(04), 87-109. 10.1501/SBFder_0000002185

Gray, P. H. (2001). The impact of knowledge repositories on power and control in the workplace, Information TechnologyandPeople, 14(4), 368-384, https://doi.org/10.1108/09593840110411167.

Gurteen, D. (1999). Creating a knowledge sharing culture. Knowledge Management Magazine, 2(5), 1-4. $16 \quad$ Aralk 2020 tarihinde file://C:/Users/hp/Downloads/Creating\%20a\%20Knowledge\%20Sharing\%2 0Culture\%20(1).pdf adresinden erişildi.

Güğerçin, U. (2018). Mentorluktan Ters Mentorluğa. Ankara: Akademisyen

Hofstede, G. (1984). Culture's consequences: International differences in work-related values (Vol. 5): Sage.

Hox, J. (1998). Multilevel modeling: When and why. In Classification, data analysis, and data highways (pp. 147-154): Springer.

Hsu, M. H., ve Chang, C. M. (2014). Examining interpersonal trust as a facilitator and uncertainty as an inhibitor of intra-organisational knowledge sharing. Information Systems Journal, 24(2), 119-142. https://doi.org/10.1111/isj.12000

Huo, W., Cai, Z., Luo, J., Men, C.ve Jia, R. (2016). Antecedents and intervention mechanisms: a multi-level study of RandD team's knowledge hiding behavior. Journal of Knowledge Management. doi: https://doi.org/10.1108//KM-11-2015$\underline{0451}$

Ikiugu, M., Pollard, N., Cross, A., Willer, M., Everson, J.ve Stockland, J. (2012). Meaning making through occupations and occupational roles: A Heuristic study of worker-writer histories. British Journal of Occupational Therapy, 75(6), 289-295. doi:10.4276/030802212x13383757345229

Ipe, M. (2003). Knowledge sharing in organizations: A conceptual framework. Human $\begin{array}{llll}\text { Resource Development } & \text { 2(4), }\end{array}$ https://doi.org/10.1177/1534484303257985 
Jha, J. K.ve Varkkey, B. (2018). Are you a cistern or a channel? Exploring factors triggering knowledge-hiding behavior at the workplace: evidence from the Indian RandD professionals. Journal of Knowledge Management, 22(4), 824-849 :https://doi.org/10.1108//KM-02-2017-0048

Jussila, I., Tarkiainen, A., Sarstedt, M.ve Hair, J. F. (2015). Individual psychological ownership: concepts, evidence, and implications for research in marketing. Journal of Marketing Theory and Practice, 23(2), 121-139. doi:10.1080/10696679.2015.1002330

Kaplan, D. ve George, R. (1995). A study of the power associated with testing factor mean differences under violations of factorial invariance. Structural Equation Modeling: A Multidisciplinary Journal, 2(2), 101-118. doi:10.1080/10705519509539999

Keegan, S. (2015). The psychology of fear in organizations: How to transform anxiety into well-being, productivity and innovation: Kogan Page Publishers. 4 Eylül 2020 tarihinde https://www.amazon.com/Psychology-Fear-Organizations-Wellbeing-Productivity/dp/0749472545 adresinden erişildi.

Kish-Gephart, J. J., Detert, J. R., Treviño, L. K.ve Edmondson, A. C. (2009). Silenced by fear:: The nature, sources, and consequences of fear at work. Research in Organizational Behavior, 29, 163-193. doi:https://doi.org/10.1016/j.riob.2009.07.002

Kligyte, V., Connelly, S., Thiel, C.ve Devenport, L. (2013). The influence of anger, fear, and emotion regulation on ethical decision making. Human Performance, 26(4), 297-326. https://doi.org/10.1080/08959285.2013.814655

Kotrlik, J.ve Higgins, C. (2001). Organizational research: Determining appropriate sample size in survey research appropriate sample size in survey research. Information Technology, Learning, and Performance Journal, 19(1), 43. 11 Ekim 2020 tarihinde https://rabu.pw/1593987451.pdf adresinden erişildi.

Köseoğlu, M. A., Gider, Ö.ve Ocak, S. (2011). Bilgi paylaşımı tutumunu etkileyen faktörler nelerdir? Bir kamu hastanesi örneği. Eskişehir Osmangazi Üniversitesi İ̈BF Dergisi, $6(1)$ 215-243. http://www.acarindex.com/dosyalar/makale/acarindex-1423880304.pdf

Labafi, S. (2017). Knowledge hiding as an obstacle of innovatıon in organizations a qualitative study of software industry. AD-minister, 131148.http://dx.doi.org/10.17230/ad-minister.30.7

Lachman, M. E. ve Weaver, S. L. (1998). Sociodemographic variations in the sense of control by domain: Findings from the MacArthur studies of midlife. Psychology and Aging, 13(4), 553-562. doi:10.1037/0882-7974.13.4.553 
Lin, C.-P. (2007). To share or not to share: Modeling tacit knowledge sharing, its mediators and antecedents. Journal of Business Ethics, 70(4), 411-428. https://doi.org/10.1007/s10551-006-9119-0

Liu, J., Wang, H., Hui, C.ve Lee, C. (2012). Psychological Ownership: How Having Control Matters. Journal of Management Studies, 49(5), 869-895. https://doi.org/10.1111/j.1467-6486.2011.01028.x

Liu, Y., Zhu Julie, N. Y.ve Lam Long, W. (2020). Obligations and feeling envied: a study of workplace status and knowledge hiding. Journal of Managerial Psychology, 35(5), 347-359. doi:10.1108/JMP-05-2019-0276

McAdam, R.ve Reid, R. (2000). A comparison of public and private sector perceptions and use of knowledge management. Journal of European Industrial Training, 24(6), 317- 329. https://doi.org/10.1108/03090590010346424

McDermott, R. (1999). Why Information technology inspired but cannot deliver knowledge management. California Management Review, 41(4), 103-117. doi:10.2307/41166012

McElroy, M. (1999). Second-generation knowledge management. Knowledge Management, $\quad 10(10), \quad 86-88 . \quad$ http://www.learningorg.com/docs/McElroy2ndGenKM.pdf adresinden erişildi.

McNeish, D. M.ve Stapleton, L. M. (2016). The effect of small sample size on two-level model estimates: A review and illustration. Educational Psychology Review, 28(2), 295-314. doi:10.1007/s10648-014-9287-x.

Metin, S. (2020). İşletmelerde bilgi yönetimi ve kurumsal içerik yönetimi, Erzincan Binali Yıldırım Üniversitesi İktisadi ve İdari Bilimler Fakültesi Dergisi, 2 (2), s. 1-8.,doi: 10.46482/ebyuiibfdergi.756753.

Mobbs, D., Adolphs, R., Fanselow, M. S., Barrett, L. F., LeDoux, J. E., Ressler, K.ve Tye, K. M. (2019). Viewpoints: Approaches to defining and investigating fear. $\mathrm{Na}-$ ture neuroscience, 22(8), 1205-1216. https://doi.org/10.1038/s41593-019-0456-6

Monteiro, L. F., Arvidsson, N.ve Birkinshaw, J. (2008). Knowledge flows within multinational corporations: Explaining subsidiary isolation and its performance $\begin{array}{llll}\text { implications. } & \text { Organization }\end{array}$ https://doi.org/10.1287/orsc.1070.0264

Navimipour, N. J.ve Charband, Y. (2016). Knowledge sharing mechanisms and techniques in project teams: Literature review, classification, and current trends. Computers in Human Behavior, 62, 730742::https://doi.org/10.1016/j.chb.2016.05.003 
Nonaka, I.ve Toyama, R. (2015). The knowledge-creating theory revisited: knowledge creation as a synthesizing process. In The essentials of knowledge management (pp. 95-110): Springer. https://doi.org/10.1057/9781137552105_4

Olckers, C.ve Du Plessis, Y. (2012). The role of psychological ownership in retaining talent : a systematic literature review : original research. SA Journal of Human Resource Management, 10(2), 1-18.22 Eylül 2020 tarihin-

dehttps:/www.ingentaconnect.com/content/sabinet/sajhrm/2012/00000010/0 0000002/art00014 adresinden erişildi.

Ozler, H., Yilmaz, A.ve Ozler, D. (2008). Psychological ownership: An empirical study on its antecedents and impacts upon organizational behaviors. Problems and Perspectives in Management(6, Iss. 3), 38-47. 26 Kasim 2020 tarihinde file://C:/Users/hp/Downloads/prperman_2008_6_3_7\%20(5).pdf erişildi.

Öhman, A.ve Mineka, S. (2001). Fears, phobias, and preparedness: toward an evolved module of fear and fear learning. Psychological Review, 108(3), 483-522. doi: 10.1037//0033-295X.108.3.483

Özdemirci, F., Aydın C. (2007). Kurumsal bilgi kaynaklanı ve bilgi yönetimi, Türk Kütüphaneciliği, 21(2), 164-185, 25 Aralik 2020 tarihinde https:/dergipark.org.tr/en/download/article-file/815119 adresinden erişildi.

Peng, H. (2013). Why and when do people hide knowledge? Journal of Knowledge Management, 17(3), 398-415. doi:10.1108/JKM-12-2012-0380

Pierce, J. L., Kostova, T.ve Dirks, K. T. (2001). Toward a Theory of Psychological Ownership in Organizations. Academy of Management Revieww, 26(2), 298-310. doi:https://doi.org/10.5465/amr.2001.4378028

Pierce, J. L., Kostova, T.ve Dirks, K. T. (2003). The State of psychological ownership: Integrating and extending a century of research. Review of General Psychology, 7(1), 84-107. doi:10.1037/1089-2680.7.1.84

Powers, V. J. (1999). Xerox creates a knowledge-sharing culture through grassroots efforts. Knowledge Management in Practice, 18(1), 1-4.

Pradhan, S., Srivastava, A.ve Mishra Dharmesh, K. (2019). Abusive supervision and knowledge hiding: the mediating role of psychological contract violation and supervisor directed aggression. Journal of Knowledge Management, 24(2), 216234. doi:10.1108/JKM-05-2019-0248

Razmerita, L., Kirchner, K.ve Nielsen, P. (2016). What factors influence knowledge sharing in organizations? A social dilemma perspective of social media communication. Journal of Knowledge Management, 20(6), 1225-1246. doi:10.1108/JKM-03-2016-0112 
Renzl, B. (2008). Trust in management and knowledge sharing: The mediating effects of fear and knowledge documentation. Omega, 36(2), 206-220. doi:https://doi.org/10.1016/j.omega.2006.06.005

Riege, A. (2005). Three-dozen knowledge-sharing barriers managers must consider. Journal of Knowledge Management, 9(3), 18-35. doi:10.1108/13673270510602746

Rogers, R. W. (1975). A protection motivation theory of fear appeals and attitude change1. The Journal of Psychology, 91(1), 93-114. doi:10.1080/00223980.1975.9915803

Serenko, A.ve Bontis, N. (2016). Understanding counterproductive knowledge behavior: antecedents and consequences of intra-organizational knowledge hiding. Journal of Knowledge Management, 20(6), 1199-1224. doi:10.1108/JKM-05-20160203

Siemsen, E., Roth, A. V., Balasubramanian, S.ve Anand, G. (2009). The Influence of psychological safety and confidence in knowledge on employee knowledge sharing. Manufacturing and Service Operations Management, 11(3), 429-447. doi:10.1287/msom.1080.0233

Snijders, T. A. B. ve Bosker, R. J. (1993). Standard errors and sample sizes for two-level research. Journal of Educational Statistics, 18(3), 237-259. doi:10.3102/10769986018003237

Şentürk, F. K.ve Carman, Y. (2019). Örgüt kültürünün ve örgütsel adaletin bilgi paylaşımı üzerine etkisi: Bir devlet üniversitesi örneği. Alanya Akademik Bakış, 3(1), 1-18. https://doi.org/10.29023/alanyaakademik.492117

Tohidinia, Z.ve Mosakhani, M. (2010). Knowledge sharing behaviour and its predictors. Industrial Management and Data Systems, 110(4), 611-631. doi:10.1108/02635571011039052

Vajjhala, N. R.ve Baghurst, T. (2014). Influence of cultural factors on knowledge sharing in medium-sized enterprises within transition economies. International Journal of Knowledge Management Studies, 5(3-4), 304-321. doi:10.1504/ijkms.2014.067235

Van Dyne, L.ve Pierce, J. L. (2004). Psychological ownership and feelings of possession: three field studies predicting employee attitudes and organizational citizenship behavior. Journal of Organizational Behavior, 25(4), 439-459. doi:https://doi.org/10.1002/job.249

Webster, J., Brown, G., Zweig, D., Connelly, C. E., Brodt, S.ve Sitkin, S. (2008). Beyond knowledge sharing: Withholding knowledge at work. "Research in personnel and human resources management", s.1-37, Emerald Group Publishing Limited. https://doi.org/10.1016/S0742-7301(08)27001-5 
Wendling, M., Oliveira, M.ve Carlos Gastaud Maçada, A. (2013). Knowledge sharing barriers in global teams. Journal of Systems and Information Technology, 15(3), 239-253. doi:10.1108/JSIT-09-2012-0054

Witherspoon, C. L., Bergner, J., Cockrell, C.ve Stone, D. N. (2013). Antecedents of organizational knowledge sharing: a meta-analysis and critique. Journal of Knowledge Management, 250-277. doi:https://doi.org/10.1108/13673271311315204

Yeşil, Ü., Bancar, A.ve Budak, G. (2015). Psikolojik sahiplik kavramına ilişkin bir literatür incelemesi. Eskisehir Osmangazi Üniversitesi Sosyal Bilimler Dergisi, 16(2), 5982. https://doi.org/10.17494/ogusbd.57630

Yeşilaydın, G.ve Bayın, G. (2015). Türkiye'de örguitsel sessizlik ile ilgili yapılan araştırmalara yönelik literatür incelemesi. Anadolu Üniversitesi Sosyal Bilimler Dergisi, 15(4), 103-120. https://doi.org/10.18037/ausbd.54497

\section{Kaynakça Bilgisi / Citation Information}

Aksay, B. (2021). Kamu ve özel sektör çalışanlarında bilgi paylaşma korkusu. OPUS-Uluslararası Toplum Araştırmaları Dergisi, 17(37), 4400-4428. DOI: $10.26466 /$ opus.868237 